The initial energy involved in waves that leave their records on gauges $8,000-16,000 \mathrm{~km}$. away must be great since the three-dimensional concentric spreading of the wave-motion into motionless water involves much loss of energy. It is safe to assume that within a distance of many hundreds of kilometres from the centre of a disturbance the energy of the tsunamic waves is a multiple of that of tidal wave motion, and that it is therefore adequate to cause the erosion in the sediments of the continental shelf.

The earthquake records of the Atlantic Ocean show that crustal unrest is now causing earthquakes at a sufficient rate to account for the submarine erosion. An important earthquake or a submarine volcanic eruption a few times a century will produce currents that on the ocean floor are as effective as the few cloudbursts per century that carve the wadis of the great desert plateaux with which the submarine valleys have been compared.

But there is good evidence that both tectonic and volcanic activity were more intense in the recent geological past, especially along the mid-Atlantic ridge. The few small parts of the latter that stand high enough to rise above sea-level, such as Iceland or the Azores or diminutive St. Paul, bear abundant evidence to that effect. It may be inferred that the erosion of the continental slope is the counterpart to the intense tectonic and volcanic activity of Quaternary time to which the mid-Atlantic ridge owes its newer and bolder features.

The systematic study of the tsunamic waves, in which the Japanese have done already much excellent work, promises results not only of scientific but also of practical value. After the Grand Banks earthquake of 1929, for example, four trans-Atlantic cables broke at once; eight others went out of service at intervals up to thirteen hours after the earthquake. The curious circumstances of these cable breaks may find their explanation in the fact that much of the damage resulted from the cumulative erosive action of the currents set up by the earthquake.

\title{
THE FIRE ALARM SYSTEM IN THE UNITED STATES
}

$\mathrm{T}$ HE request which has resulted in the development of the bulletin referred to below* on the fire alarm system in the United States originated at a convention of the International Municipal Association, held in Cleveland, Ohio, during August 30September 2, 1937. It was made officially to the United States Office of Education, and H. A. Friede was appointed to co-operate with the United States Office of Education in developing the desired analysis of the proposed work.

In practically all cities of the United States having a population not greater than 30,000 , fully automatic fire alarm systems are frequently used. In larger cities the functions to be performed by the fire alarm system are such as to require the exercise of a high degree of judgment on the part of the operator, especially when large fires or other emergencies occur. Up to the present time, the requirements of the men employed in fire alarm bureaux have received little attention from those who are promoting and operating training programmes for the personnel of the departments. In many cities the bureau is organized and operated as an independent unit of the city's entire programme of public safety. When this is the case, the co-operation between the chief engineer of the fire department and the superintendent of the fire alarm bureau should be close and effective. In cities where the fire alarm bureau is under the chief, full confidence should also prevail. In some cities the fire alarm bureau is responsible not only for the operation of the fire alarm system itself, but also for the police telegraph and the municipal telephone and radio communication systems, through which all fire and police stations, and police and fire depart. ment motor-cars may be reached in any desired combination, with practically no delay.

The two principal bases for the rating of responsibilities show (1) the degree to which specific responsibilities are delegated and (2) the degree to

* The Fire Alarm System : an Analysis of the Work of the Fire Alarm Bureau, with a Discussion of the Problems of Training likely to be Encountered. By Frank Cushman and $\mathrm{H}$. A. Friede. (U.S. Department of the Interior: Office of Education. Vocational Division Bulletin No. 207. Trade and Industrial Series No. 58. (Washington, D.C. : Government Printing Office, 1940.) 15 cents. which each responsibility involved represents trouble, difficulty or worry. A practical and simple method of rating responsibilities from this point of view is illustrated by means of a graph. An arbitrary scale from 0 to 10 is used. A rating of 10 on this scale means that the responsibility is as completely delegated as it can be, whilst a rating of 0 indicates that the superintendent believes that he cannot delegate to anyone the responsibility for doing that which is necessary in order for him to discharge the duty satisfactorily.

In fairly large cities, there are four men in each of the following three classifications: chief operator, assistant chief operator and telephone operator. This makes it possible to have three shifts, with an extra man for each job available to take care of the work in cases of absence due to sickness, vacations and leave. To the fire alarm operator, technical and operating proficiency in the handling of radiotelephone equipment is essential, seeing that in most cities he is called on to operate the radiotelephone equipment. A knowledge of the geography of the city, similar to that required of the fire alarm operator, is also important for the telephone operator. The man on this job should make every effort to perfect his knowledge of the city and of all its important details while serving in this position and awaiting promotion to the assistant chief operator's job. Analysis charts are given of the various kinds of knowledge which those filling junior posts are supposed to have.

When it appears necessary to provide some training to secure greater efficiency of operation, the mistake is often made of setting up programmes of a more or less general character. As examples of this, mention is made of a general course of instruction in the principles of electricity or a series of lectures for fire alarm personnel on the history of the development of fire alarm systems. The kind of information that is really useful to the operatives and to the station is given in appendixes illustrated by clear line diagrams. These deserve special study by everyone interested in fire alarm stations, and clearly indicate the trend of future development. 